\title{
Hari metalikoetan eta arku elektrikoan oinarritutako fabrikazio-gehigarriko WAAM teknologiaren oinarriak eta aplikazioak
}

\author{
(Wire Arc Additive Manufacturing (WAAM) technology \\ fundamentals and applications)
}

\author{
Eider Aldalur*1, Asier Panfilo ${ }^{2}$, Alfredo Suárez ${ }^{1}$, Jone M. Ugartemendia ${ }^{2}$ \\ ${ }^{1}$ TECNALIA, Basque Research and Technology Alliance (BRTA) \\ ${ }^{2}$ Bilboko Ingeniaritza Eskola (UPV/EHU), Meatze Metalurgia Ingeniaritza \\ eta Materialen Zientzia Saila
}

\begin{abstract}
LABURPENA: Fabrikazio-gehigarria geruzaz geruza piezak eratzean oinarritzen den produkzio-kontzeptu berria da. Fabrikazio-gehigarriaren barneko teknikek duten izaera dela eta, orain artean fabrikazio-teknika tradizionalek inposatutako diseinu-mugak gainditzea ahalbidetzen dute. Material mota anitzetan lan egin dezaketen arren, lan honetan material metalikoetan oinarritutako fabrikazio-gehigarriko teknikak azalduko dira. Horien artetik, arku eta hari bidezko fabrikazio gehigarrian (ingelesez, Wire Arc Additive Manufacturing (WAAM)) arreta berezia ezarriko da, erakusten dituen abantailak direla eta. Lan honen helburu nagusia WAAM teknologia metalen fabrikazio-gehigarriaren barruan kokatzea da, teknologia honen deskribapena eginez eta hark industrian dituen hainbat aplikazio azalduz. Horretarako, lehenik eta behin, metalen fabrikazio-gehigarriko prozesu nagusiak azalduko dira, eta materiala elikatzeko eraren araberako sailkapen bat aurkeztuko da. Ondoren, WAAM prozesuaren deskribapena eta xehetasunak azalduko dira. Jarraian, WAAM teknologiaren bidez piezak fabrikatzeko erabilitako ekipamendua eta aplikazio eremu bakoitzeko (fabrikazio zuzena, ez-zuzena eta konponketak) adibide industrial erreal bat azalduko da. Fabrikazio zuzenean, 5356 aluminio-aleazioan topologikoki optimizatutako diseinua duen dorrearen fabrikazioa azalduko da, diseinu originalarekin alderatuta \% $31 \mathrm{ko} \mathrm{pisu} \mathrm{aurrez-}$ kia lortuz. Fabrikazio ez-zuzenean, ER70S-6 altzairuan tamaina handiko molde baten fabrikazioa aipatuko da. Azkenik, konponketei dagokienez, H13 altzairuzko molde higatu bat WAAM teknologiaren bidez nola konpondu den azalduko da.
\end{abstract}

HITZ GAKOAK: fabrikazio-gehigarria, WAAM, aleazio metalikoak

ABSTRACT: Additive Manufacturing (AM) is a new production concept based on the formation of parts layer by layer. Thanks to its nature, the design limitations imposed by traditional manufacturing techniques can be overcome. Although, parts can be manufactured in many different types of materials employing this technology, this paper will only focus on additive manufacturing techniques based on metallic materials. Due to the advantages it presents, special attention will be paid to the Wire Arc Additive Manufacturing (WAAM) technique. The main objective of this work is to place WAAM technology within the metallic additive manufacturing, describing it and explaining its main industrial applications. To this end, first, the main processes of metallic additive manufacturing will be described and classification according to the way that the material is fed will be presented. Secondly, WAAM process deep description and details are given. Thirdly, equipment used in the WAAM manufacture of parts is mentioned and various real use cases focused on each application area (direct manufacturing, indirect manufacturing and repairs) are presented. In direct manufacturing, the manufacture of a tower with a topologically optimized design in 5356 aluminium alloy will be explained, achieving a weight saving of $31 \%$ compared to the original design. In indirect manufacturing, manufacturing of a large-sized cast in ERTOS-6 steel is presented. Finally, regarding repairs, it will be explained how to repair an eroded H13 steel cast using WAAM technology.

KEYWORDS: Additive Manufacturing, Wire Arc Additive Manufacturing, Metal alloys.

* Harremanetan jartzeko / Corresponding author: Eider Aldalur. TECNALIA, Basque Research and Technology Alliance (BRTA), Gipuzkoako Parke Zientifiko eta Teknologikoa, E20009, Donostia. - eider.aldalur@tecnalia.com - https://orcid.org/0000-00015030-043X

Nola aipatu / How to cite: Aldalur, Eider; Panfilo, Asier; Suárez, Alfredo; Ugartemendia, Jone M. (2021). «Hari metalikoetan eta arku elektrikoan oinarritutako fabrikazio-gehigarriko WAAM teknologiaren oinarriak eta aplikazioak». Ekaia, 40, 2021, 345-360. (https://doi.org/10.1387/ekaia.22367).

Jasotze-data: 2020, abenduak 22; Onartze-data: 2021, otsailak 22.

ISSN 0214-9753 - eISSN 2444-3581 / (c) 2021 UPV/EHU

(i) $\odot$ Lan hau Creative Commons Aitortu-EzKomertziala-LanEratorririkGabe 4.0 Nazioartekoa lizentzia baten mende dago 


\section{SARRERA}

Fabrikazio-gehigarria da materiala geruzaz geruza ezartzean oinarritzen den eta aldaera ugari dituen fabrikazio-tekniken multzoa. Teknika multzo honek geometria, konplexutasun eta akabera anitzeko piezak eratzea ahalbidetzen du, horretarako piezaren hiru dimentsioko ordenagailuz lagundutako diseinu (CAD) batetik abiatuta.

Fabrikazio-gehigarriak 4.0 Industriaren garapenak planteatzen duen ekoizpen-sistemaren eboluzioari erantzuten dio [1]. Izan ere, teknika tradizionalek lehengai-bloke batetik abiatuz, piezaren azken geometria lortzeko materiala erauzten duten bitartean, fabrikazio-gehigarriak materiala soilik behar den lekuan eta behar den kantitatean ezartzen du, prozesuaren kostua murriztuz eta materialaren erabilera-efizientzia handituz. Beraz, fabrikaziogehigarria 4.0 Industriaren garapenerako gako nagusietako bat izan daiteke, eta horren arrakastaren neurria ezar lezake.

Nahiz eta fabrikazio-gehigarriko teknikak material mota anitzekin (polimeroak, zeramikoak, konpositeak, etab.) lan egiteko baliozkoak izan, artikulu honetan material metalikoetan oinarritutako fabrikazio-gehigarriko teknikak aztertuko dira. Gaur egun, material metalikoetan oinarritutako fabrikazio-gehigarriko teknikek material- eta energia-aurrezte handia ahalbidetzen dute, eta kostua eta ingurumen-inpaktua murrizteko aukera eskaintzen dute [2]. Gainera, aukera egokia dira geometria bereziak eta konplexuak fabrikatzeko, edo balio erantsi altuko piezak konpontzeko. Izan ere, teknologia horien bidez, zehaztasun altuko piezak fabrika daitezke propietate mekaniko egokiak mantenduz. Horrez gain, osagai ugariko piezak osagai bakarrean fabrikatzea ere ahalbidera dezakete [3].

Hala ere, gaur egun, material metalikoetan oinarritutako fabrikaziogehigarriko teknikek mugak dituzte masa-produkziorako, ekoizpenabiadura eta errepikakortasuna, orokorrean, baxuak baitira. Hala, oro har, teknika horiek oraindik pieza unitarioetara eta konponketa-aplikazioetara mugatzen dira, eta gaur egungo erronka nagusia da horiek masa-produkziora egokitzea [1]. Horretarako, teknika multzo horren fabrikazio-aldagaiak optimizatzea bilatzen da. Era berean, fabrikazio-metodo horiek materialen mikroegituran eta propietate mekanikoetan duten eragina ikertzen da. Izan ere, horiek kontrolatzea lortzen bada, posible izango da prozesuen estandarizazioa eta teknika horiek fabrikazio-teknika tradizionalen lekuan erabiltzea.

\section{FABRIKAZIO-GEHIGARRIKO TEKNIKAK}

Material metalikoetan oinarritutako fabrikazio-gehigarriko metodo ezberdinak hainbat irizpideren arabera sailka daitezke; hala nola, energia-iturria, 
materiala elikatzeko era edota elikatutako materialaren formatua. Materiala elikatzeko eraren arabera, hiru talde nagusi bereizten dira: Hauts-ohearen fusioa (Powder Bed Fusion, PBF), Hauts-elikatzedun deposizioa (Powder Feed Systems, PFS) eta Hari-elikatzedun deposizioa (Wire Feed Systems, WFS). Azken bietan, energia eta materiala zuzenean sartzen dira prozesuan, eta biek batera energiaren ezartze zuzena (Direct Energy Deposition, DED) izeneko teknika multzoa osatzen dute. Beraz, energiaren ezartze zuzenak bi aldaera nagusi ditu; batetik, materiala hari-formatuan elika daiteke, eta, bestetik, hauts-formatuan [4].

Bestalde, energia-iturriari dagokionez, arku elektrikoa, laser izpia edota elektroi sorta, teknikoki «e-beam» bezala ezaguna, erabil daitezke. Arku elektrikoa da energia-iturri efizienteena, eta erabilitako energiaren \% 90 inguru aprobetxatzen du. Laserraren efizientzia, aldiz, baxuagoa da, \% 35 artekoa, eta elektroi sortarena \% 15-20 artekoa [5].

Jarraian, aipatutako teknika bakoitzaren oinarriak azalduko dira. 1. irudian metodo bakoitzaren irudikapen eskematikoa erakusten da, eta 1. taulan, berriz, horien abantaila eta desabantaila nagusiak laburbiltzen dira, hiru teknika multzo nagusien ikuspegi orokor bat izateko. Bakoitza, bere ezaugarrien eta mugen arabera, aplikazio ezberdinetan erabiltzen da, eta material zehatz batzuentzat da aproposa.

\subsection{Hauts-ohearen fusioa (Powder Bed Fusion, PBF)}

Teknika honetan, lehenik eta behin, hauts metalikozko geruza bat laningurunean ezartzen da, arrabola baten bidez. Jarraian, energia-iturri kontzentratu batek (laserra edo elektroi sorta) geruza honetako hautsa selektiboki urtu edo sintetizatzeko energia hornitzen du (ikusi 1.(a) irudia). Metalen kasuan, urtzea da ohikoena [6]. Ondoren, era kontrolatuan, pistoi baten laguntzaz lan-ingurunea geruza baten lodieran jaitsi eta, berriz ere, arrabolaren bidez hauts-geruza berri bat ezartzen da aurrekoaren gainean. Jarraian, energia-iturri kontzentratua erabiliz, hauts metalikoa solidifikatzen da piezaren geruza horretako geometriari jarraiki, eta, hala, prozesu hori behin eta berriz errepikatuta pieza geruzaz geruza osatzen da. Behin prozesua amaituta, pieza osatua lan-inguruneko hautsetatik ateratzen da. Laserra erabiltzen denean, hautsa urtzen den atmosfera inertea izan behar da. Aldiz, energia-iturria elektroi sorta denean, prozesua ingurune hutsean gauzatu behar da [4].

\subsection{Energiaren ezartze zuzena (Direct Energy Deposition, DED)}

DED teknika multzoaren barruan sartzen da energia-iturriak materiala elikatzen den aldi berean urtzen duen prozesu oro. Material me- 
talikoa hauts (PFS) edo hari (WFS) formatuan elika daiteke. Materiala urtzeko energia-iturri gisara laserra, elektroi sorta edo arku elektrikoa erabil daitezke. Hala, energia-iturria eta materiala elikatzeko ekipamendua sistema mugikor baten (beso robotiko bat, Gantry makina bat, makina kartesiar bat, etab.) gainean muntatzen dira, eta sistema horren bidez materiala nahi den lekuan ezarriko da. Gainera, metala erreaktiboa bada, atmosfera inerte batek babestuta egin beharko da lan, oxidazioa saihesteko [7].

\subsubsection{Hauts-elikatzedun deposizioa (Powder Feed System, PFS)}

Teknika multzo honen barnean ezagunena energia-iturri gisa laserra erabiltzen duena da, laser bidezko metala jalkitzeko teknologia (Laser Metal Deposition, LMD) moduan ezaguna. Teknologia horretan, hauts metalikoa tobera baten bidez elikatzen da, eta lente batek bideratutako laser izpiaren bidez urtzen da (ikus 1.(b) irudia). Materiala elikatzen eta urtzen ari den bitartean, piezaren forma lortzeko bi alternatiba daude: pieza mugi daiteke tobera geldi egonik, edo sistema mugikorraren bidez tobera mugi daiteke pieza geldi dagoen bitartean [8]. Prozesu hori geruzaz geruza errepikatzen da, hiru dimentsioko pieza eratu arte.

\subsubsection{Hari-elikatzedun deposizioa (Wire Feed System, WFS)}

Teknika mota honetan, materiala hari bezala elikatzen da, eta energia-iturri batek (laserra, elektroi sorta edo arku elektrikoa) urtu egiten du (ikus 1.(c) irudia). Multzo honetan erabiliena arku eta hari bidezko fabrikazio-gehigarri (WAAM) bezala ezaguna den teknika da, arku elektrikoa energia-iturri gisara erabiltzen duena, hain zuzen ere. WAAM teknika soldadura automatikoaren printzipioetan oinarritzen da; hain zuzen ere, oinarri-material baten gainean geruzak gainezarriz fabrikatzen dira piezak [8].

Beraz, metodo horien aukerak eta mugak aztertuta (ikus 1. taula), ondorioztatzen da metalen fabrikazio-gehigarriak gainditu beharreko erronka ugari dituela etorkizun hurbilean. Esaterako, prozesuko aldagaiak kontrolatu behar dira, hala nola materialaren konposizio kimikoa, hozte-prozesuko denbora eta tenperatura, babes-atmosferaren konposizioa eta materialaren ezarpen-tasa.

Izan ere, aldagai horien ondorio dira piezaren azken propietateak; esaterako, mikroegitura eta aleen orientazioa, piezaren gainazal-akabera, erresistentzia mekanikoa edo nekearekiko erresistentzia. Gainera, kontuan hartzekoak dira aldagaien kontrol okerrak eragiten dituen ondorioak; hala nola, porositatea, hondar-tentsioak, oinarri-materialarekiko itsaspen okerra, edo propietate mekaniko eskasak [6]. 


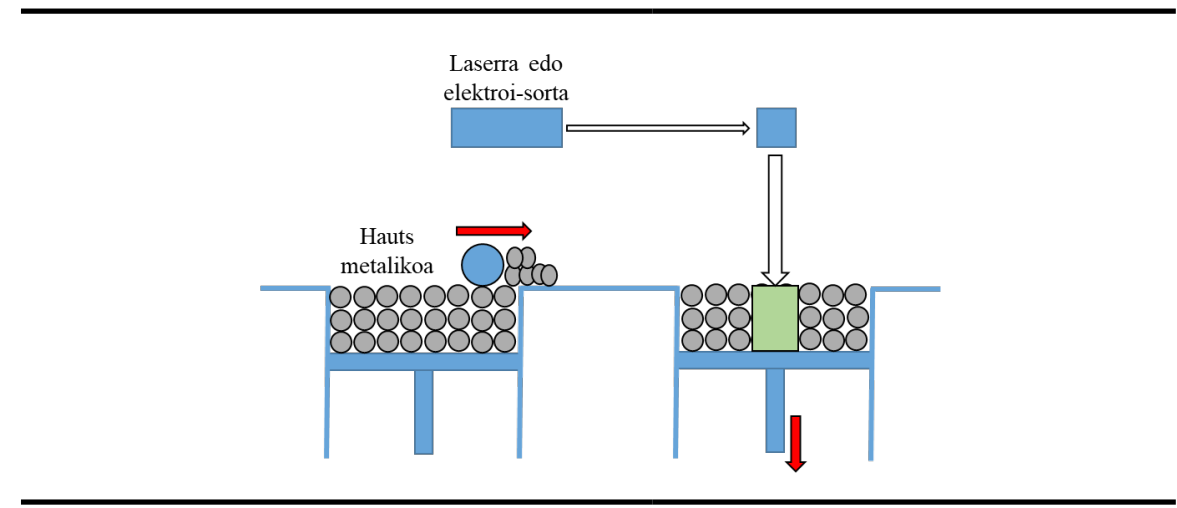

(a)

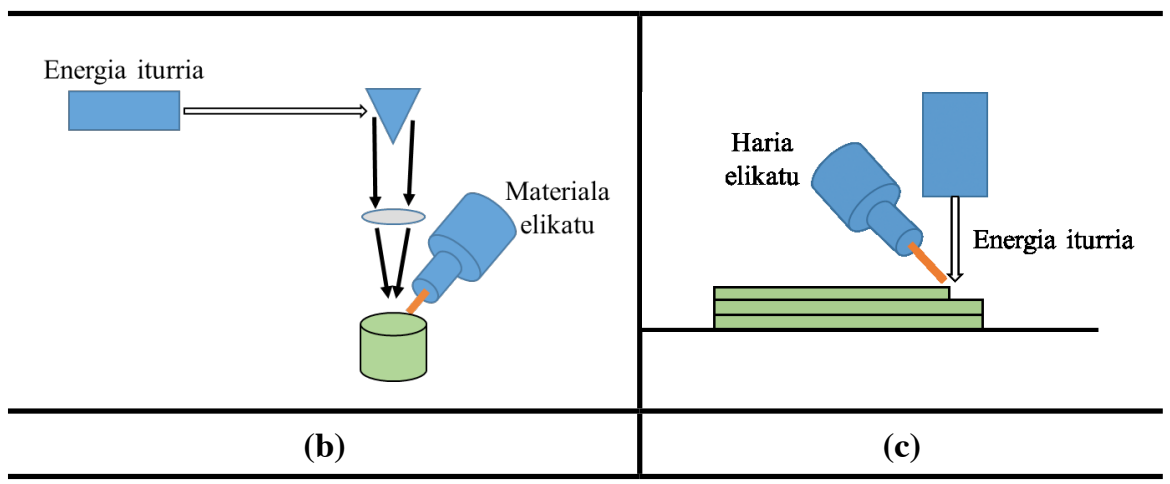

1. irudia. Metaletan oinarritutako fabrikazio-gehigarriko tekniken irudikapen eskematikoa: (a) Hauts-ohearen fusioa (PBF); (b) Hauts-elikatzedun deposizioa (PFS); (c) Hari-elikatzedun deposizioa (WFS).

Bestalde, gaur egun ikusi da metalen fabrikazio-gehigarria prototipoen diseinura, balio erantsi altuko pieza txikien ekoizpenera eta balio erantsi altuko piezen konponketara mugatzen dela [1]. Beraz, fabrikazio-metodo tradizionalen lekua hartzeko eta 4.0 Industriaren oinarrizko elementu bilakatzeko, fabrikazio-gehigarriak dituen oztopoak gainditu eta masa-produkziora egokitu daitekeela frogatu beharko du. 


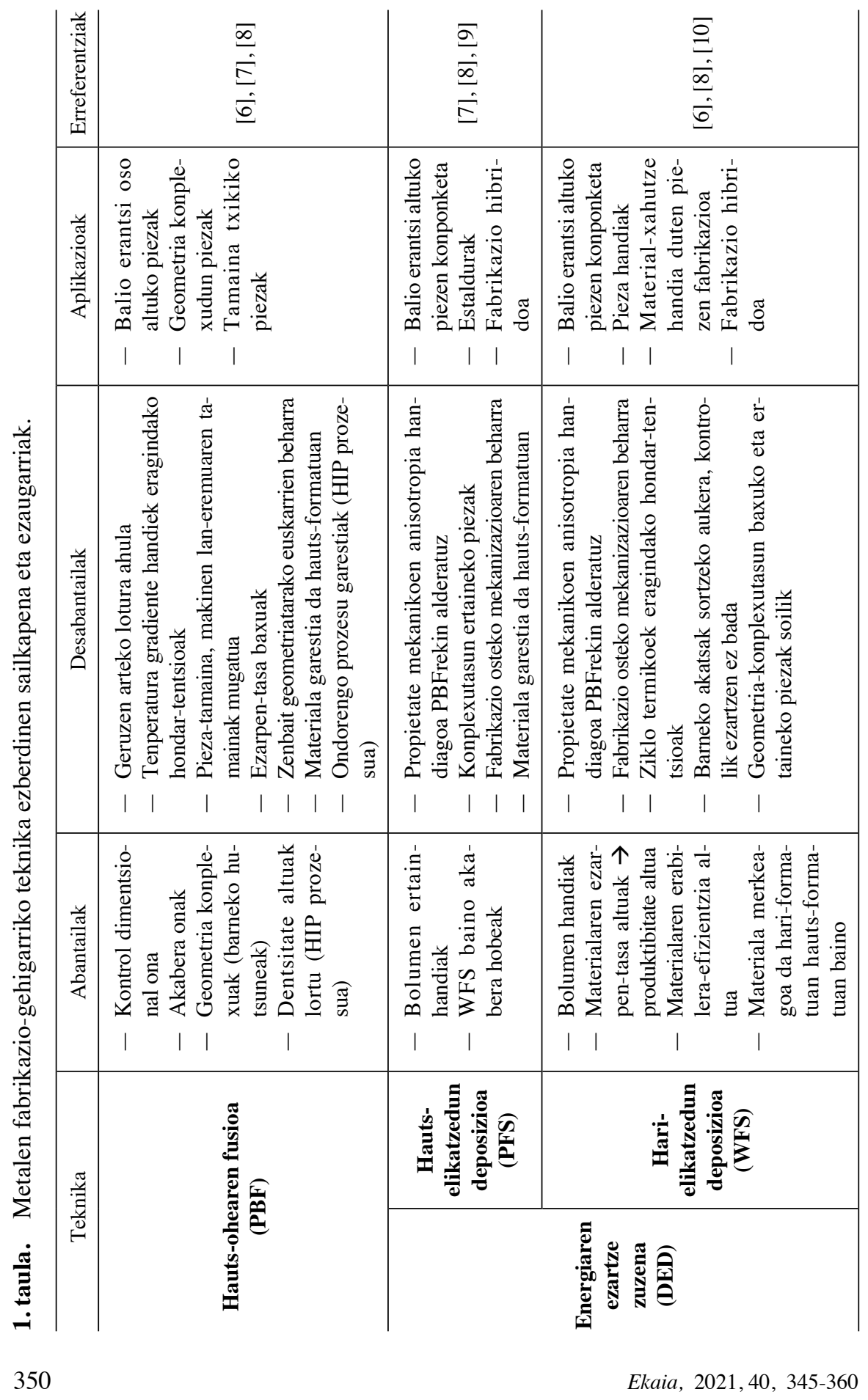




\section{ARKU ETA HARI BIDEZKO FABRIKAZIO-GEHIGARRIA (WAAM)}

WAAM fabrikazio-teknika aurreko atalean aipatutako hari-elikatzedun deposizioko teknika multzoaren barnean sailkatzen da. Funtsean, soldadura-prozesu automatiko baten antzekoa da, eta hari moduan elikatutako materiala arku elektriko baten bidez urtzen da, 2. irudian ikusten den bezala. Urtutako materiala oinarri-materialean ezartzen da soldadura-kordoi bat eratuz, eta kordoiak gainezarriz forma anitzetako piezak fabrika daitezke [11]. Azkenik, gainazala mekanizatzen da, akabera egokiak lortzeko.

Bero-iturriaren arabera, hiru WAAM prozesu mota bereizten dira: arku bidezko gas metal soldadura (Gas Metal Arc Welding, GMAW), arku bidezko gas tugsteno soldadura (Gas Tungsten Arc Welding, GTAW) eta plasma bidezko soldadura (Plasma Arc Welding, PAW). Artikulu honetan, GMAW teknologian oinarritutako WAAM prozesua aztertuko da. GMAW teknologiak elektrodo suntsikorra du; hau da, elikatzen den haria bera da elektrodoa. Beste bi teknologietan, aldiz, elektrodoa iraunkorra da (gehienetan tungstenozkoa), ez da kontsumitzen, eta haria independenteki elikatzen da, haria elikatzeko sistema baten bidez. GMAW teknologiak ezarpen-tasa altuagoak eskaintzen ditu, baina arku elektriko ezegonkorra eta zipriztinak sor ditzake [2].

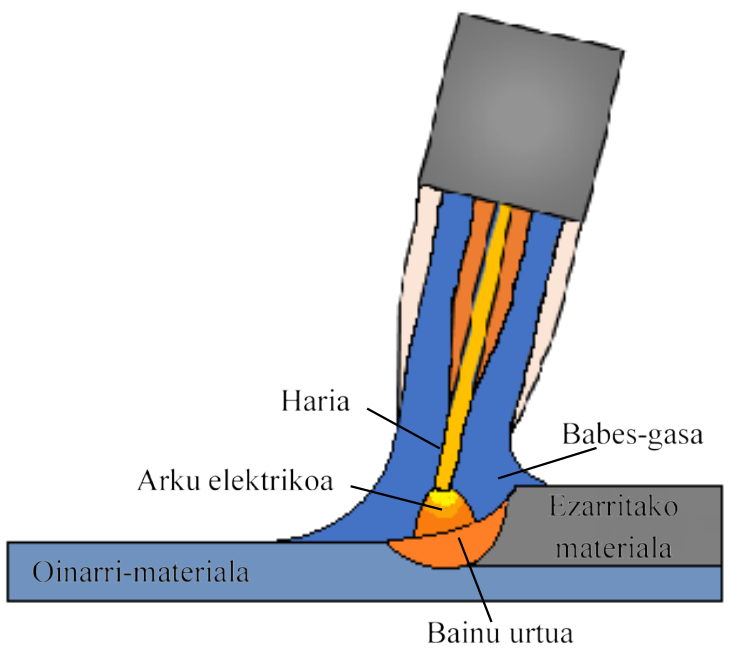

2. irudia. GMAW prozesuaren errepresentazio grafikoa. 
WAAMak konplexutasun ertain eta baxuko geometrien fabrikazioa ahalbidetzen du; beraz, mugak ditu diseinu oso konplexuentzat. Hala ere, materialaren ezarpen-tasa altua du, eta, gainerako fabrikazio-gehigarriko teknikekin konparatuta, oso metodo produktiboa da. Gainera, tamaina handiko piezak egin daitezke, eta materiala aurreztu, eroste-erabiltze tasa -ingelesez, Buy To Fly (BTF) - bikaina eskaintzen baitu, 2 baino txikiagoa. Hala ere, ezarpen-tasa altuegia bilatzeak BTF handitzea eragiten du, eta, hortaz, ezarpen-tasa balio ertainetan mantentzea gomendatzen da [3]. Materialaren arabera, ezarpen-tasak 1 eta $10 \mathrm{~kg} / \mathrm{h}$ artekoak izaten dira; esaterako, altzairuentzat ohiko balioa $4 \mathrm{~kg} / \mathrm{h}$ izaten da, eta titanioentzat, berriz, $1 \mathrm{~kg} / \mathrm{h}$ [12].

WAAM teknologiaren bidez soldagarria den edozein materialetan fabrika daitezke piezak. Normalean, soldadura konbentzionalerako erabiltzen diren hari metalikoak izaten dira prozesu horretako lehengaiak, eta hari horiek material anitzetan aurki daitezke. Horien artean daude titanio-aleazioak, nikel-aleazioak, altzairu herdoilgaitzak, egitura-altzairuak, aleazio baxuko altzairuak edota aluminio-aleazioak [10]. Oro har, materialaren integritate metalurgikoa ziurtatzen dela onartzen da. Bestetik, aluminioak, bereziki, porositate-arazoak izan ditzake [13]. Artikulu honetan aipatzen diren kasuetan, ER70S-6 aleazio baxuko altzairua, 0,06-0,12 arteko karbono-edukia duena, A15356 aluminioa eta H13 erraminta-altzairua erabili dira.

Bestalde, lehengai gisa hari metalikoak erabiltzeak baditu zenbait onura; izan ere, kilogramoko materialaren prezioa hari-formatuan askoz ere merkeagoa da hauts-formatuan baino ingeniaritzako zenbait materiale$\tan$ [14]. Esaterako, titanio-hautsak kilogramoko titanio-hariak baino hiru aldiz gehiago balio du [15]. Gainera, hari-formatuan dagoen materialaren kalitatea altua da, eta bere propietateak egiaztatuta daude. Horrez gain, formatu horretan material-barietate handia aurki daiteke. Bestalde, hautsen gestiorako sistema konplexuen beharrik ez da izango, eta gutxitu egiten da langilearentzako osasun-arazoen eta ingurumen arazoen arriskua ere.

Hala, teknologia konbentzionalen aldean, WAAM teknologiak erabilitako material kantitatea murrizten du, behar den lekuan behar den material kantitatea ezarriz. Modu horretara, piezako kostua murriztea lor daiteke. Kalkulatzen da WAAM prozesuan, orokorrean, lortzen den materialaren aurrezkia \% 90 ingurukoa dela, eta \% 70 ingurukoa bukaerako mekanizazioa kontuan hartzen bada [18]. Adibidez, orain gutxi, ikerketa batean, WAAM teknologia erabiliz, aireontzi baten lurrartze-tren baten mihiztadura fabrikatu zen, eta erabilitako material kantitatea $\% 78$ murriztu zen fabrikazio-teknika konbentzionalekin alderatuta. [3]

Prozesuaren alderdi teknikoei erreparatuta, garrantzitsua da aipatzea ezarpena babes-gas batekin babestutako atmosferan gauzatu behar dela, oxigenoaren eta ezpurutasunen sarrera ekiditeko, 2. irudian ikusten den bezala [17]. Ezarri nahi den materiala erreaktiboa bada, erabiltzen den 
gasa inertea izan behar da; esaterako, Argona (Ar). Bestelako materialekin, $\mathrm{CO}_{2}$ hutsarekin edota $\mathrm{Ar}-\mathrm{CO}_{2}$ nahaste batekin babestu daiteke prozesua, babes-atmosfera aktiboa sortuz. Horren arabera, GMAW prozesua Metal Inert Gas (MIG) edo Metal Active Gas (MAG) motetan bereizten da. Horrez gain, zenbait material fabrikatzeko, atmosfera kontrolatuko kamera bat erabiltzea ere gomendatzen da.

Fabrikazio-aldagai nagusia GMAW teknologian oinarritutako WAAM prozesuan, hariaren elikatze-abiadura da $(\mathrm{m} / \mathrm{min})$ eta materialaren ezarpentasa determinatzen du. Beste fabrikazio-aldagai garrantzitsu batzuk aitzinamendu-abiadura eta Stick-outa dira. Horiek sistema mugikorrean zehaztu behar dira. Izan ere, soldadurako zuzia sistema mugikor batean (Gantry makina bat, robot artikulatu bat, eta abar) muntatu behar da piezaren geometria eraikitzeko ibilbidea burutzeko. Stick-outa eta aitzinamendu-abiadura mm-tan eta $\mathrm{cm} / \mathrm{min}$-tan neurtzen dira, hurrenez hurren. Stick-outak zuzitik haria urtu gabe ateratzen den luzera neurtzen du. Aitzinamendu-abiadurak, berriz, zehazten du sistema mugikorrak zer abiadurarekin egiten duen aurrera.

Bestalde, piezek fabrikazio-prozesuan ziklo termikoak jasaten dituzte. Izan ere, arku elektrikoaren bidez materiala azkar berotzen da urtze-tenperaturaren gainetik, eta gero, bero-iturria kentzean, azkar hozten da. Ondoren, behin eta berriz, berotu eta hoztu egiten da ezarritako materiala, soldadura-kordoiak gehitzen diren heinean. Horrek hondar tentsioak sortzea eragiten du [18]. Hala, beharrezkoa da sarri geruzen artean hozte-denbora bat ezartzea, horrek produktibitatea jaitsi arren, piezak jasandako input termikoa gehiegizkoa baita bestela. Hozte-denbora kontrolatzeko, piezak momentu oro duen tenperatura pirometro baten bidez neurtzen da [19]. Horren bidez, kordoia ezarritako tenperatura baten azpitik egon arte ez da hurrengoa ezarriko. Bestela, denbora konstante bat estimatu eta ezar daiteke bi kordoiren ezarpenen artean. Batzuetan, oinarri-materiala aurretik berotzea komeni da, gradiente termikoa eta hondartentsioak agertzeko aukera murrizteko [13].

Oinarri-materiala WAAM prozesuan arreta berezia eskatzen duen aspektua da. Izan ere, ezarritako materiala oinarri-materialean sartzen da, eta interfase bat sortzen du. Normalean, oinarri-material gisara plaka metaliko lauak erabiltzen dira, eta hori piezaren parte izan daiteke edo ez. Oinarri-materiala piezaren parte bada, piezaren eta oinarriaren arteko loturak propietate jakin batzuk betetzen dituela ziurtatu beharko da. Interfase hau karakterizatzeko, soldadura-kordoia oinarri-materialean sartzen den zenbatekoa, diluzioaren bidez (azaleren arteko erlazioa) eta sakoneraren bidez kuantifika daiteke. Oinarri-materialean diluzioak sortzen duen efektua garrantzitsua da, kordoitik oinarri-materialera beroa transmititzen baita, eta hala, oinarri-materialean beroak ukitutako zonaldea sortzen da. Zonalde horretan, oinarri-materialak propietate mekanikoetan eta bere egitura metalurgikoan aldaketak jasan ditzake. 


\section{APLIKAZIOAK}

WAAM bidez fabrikatutako piezen aplikazio-eremu nagusiak dira aeronautika, ontzigintzaren sektorea eta oil \& gas sektorea. Aeronautikan, «Flaparen egitura» nerbioak edo pieza meheak egiteko erabil daiteke, edota pieza handien konponketarako. Ontzigintzaren kasuan, turbinak eta helizeak egin daitezke, esaterako.

Jada aipatu den bezala, WAAM teknologiak material kantitate minimoa ezartzen du, amaierako piezatik gertu dauden aurreformak lortzeko. Ondoren, aurreforma horiek osorik edo partzialki (gainazal funtzionalak soilik) mekanizatu beharko dira. Hala, materialaren eta energiaren funtsezko aurrezte bat lortzen da. Gainera, WAAM teknologiak, gainerako fabrikazio-gehigarriko teknikek bezala, orain artean fabrikazio-teknika tradizionalek inposatutako diseinu-mugak gainditzea ahalbidetzen du, diseinu funtzionalagoak ahalbidetuz eta, honela, piezen funtzionamendua optimizatuz, erabilitako lehengai kopurua murriztuz, galera energetikoak murriztuz eta piezen bizitza baliagarria handituz.

Beraz, beharrezkoa da fabrikazio-gehigarriko teknologia bakoitzaren erabilera-eremua zehaztea eta bakoitzarentzat aplikazio konkretuak identifikatzea, teknika tradizionalekin alderatuz kontuan hartzeko moduko irabazi ekonomikoak lortzeko. Jarraian, hiru aplikazio eremuren adibide industrial erreal bana azaltzen da, WAAM teknologiaren onurak agerian uzteko asmotan. Erabilitako ekipamendua ere zehazten da.

\subsection{Ekipamendua}

Lan honetan agertzen diren aplikazio guztietan WAAM teknika burutzeko erabili den ekipamendua 3. irudian erakusten da. Ekipamendu hori soldadura makina batek, sistema mugikor batek (kasu honetan, Fanuc Robot ARC Mate 100iC robot artikulatua) eta soldadurako zuzi batek osatzen dute.

Lehenik eta behin, fabrikazio-aldagai nagusiak diren funtzionamendu-modua eta hariaren elikatze-abiadura zehaztu behar dira soldaduramakinan (Titan XQ 400 AC puls-EWM). Hortik abiatuta, makinak beste funtzionamendu-parametroak sinergikoki zehazten ditu; harian ezarritako intentsitatea eta tentsioa, esaterako. Hau da, makinak aukeratzen den funtzionamendu-moduaren, materialaren eta babes-gas motaren arabera, barne-algoritmo baten bidez definitutako intentsitate-seinalea sortzen du, eta harian ezartzen du, arku elektrikoa sortzeko. Funtzionamendu-modu bakoitzak berezko parametroak ditu (ikus 2. taula). Kasu honetan, aplikazio ezberdinetarako hiru funtzionamendu-modu erabili dira: Pulsed-GMAW, Cold Arc eta Pulsed-AC. 


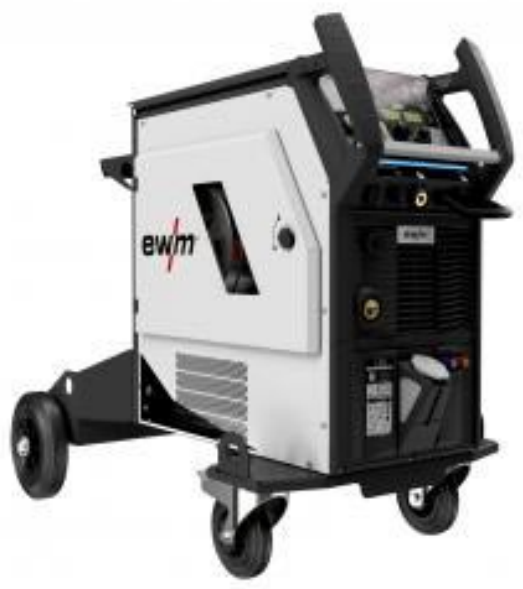

(a)

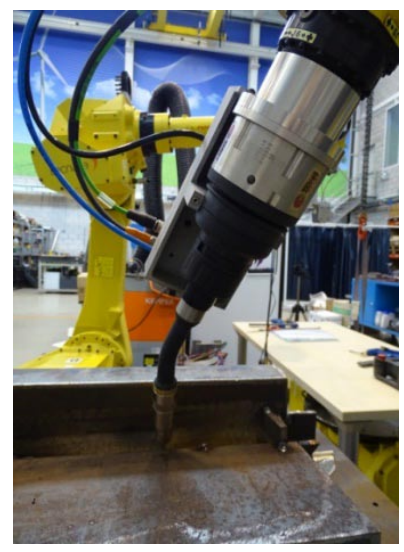

(b)

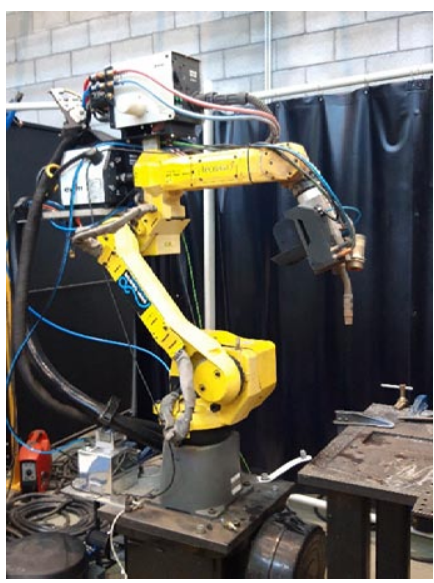

(c)

3. irudia. Soldadura ekipamendua: (a) Soldadura makina; (b) Soldadura zuzia; (c) Soldadura zuzia, robotean muntatuta.

Bestetik, robotaren bidez zuziaren (iSTM ABIROB W) mugimendua kontrolatzen da, robotaren buruan baitago zuzia muntatua. Hala, zuziak piezaren geometria eraikitzeko egin beharreko ibilbidea burutzen du. Artikulu honetan agertzen diren aplikazio guztietan, Stick-outa $15 \mathrm{~mm}$-koa da. 
2. taula. Titan XQ 400 AC puls (EWM) makinaren funtzionamendu-moduen ezaugarriak.

\begin{tabular}{c|c|c|c|c}
\hline Modua & Materiala & Gasa & $\begin{array}{c}\text { Hariaren } \\
\text { diametroa (mm) }\end{array}$ & $\begin{array}{c}\text { Hariaren elikatze } \\
\text { abiadura (m/min) }\end{array}$ \\
\hline Pulsed-GMAW & $\begin{array}{c}\text { SG2/3 } \\
(\text { ER70) }\end{array}$ & Ar \%80-90 & 1,2 & $1.5-15$ \\
\hline Cold Arc & $\begin{array}{c}\text { SG2/3 } \\
(\text { ER70) }\end{array}$ & Ar \%80-90 & 1,2 & $1-5$ \\
\hline Pulsed-AC & Al 5356 & Ar \%100 & 1,2 & $1,5-12$ \\
\hline
\end{tabular}

Piezak eratzeko, soldadura-kordoien gainezarpena gertatzen denean, robotak aitzinamendu-noranzkoa bi noranzkoetan alternatuko du. Hau da, geruza bat norabide batean ezartzen bada, hurrengoa kontrako norabidean ezarriko da, piezaren zehaztasun geometrikoa mantentzeko. Hori soilik ez da betetzen fabrikazioa modu jarraian egiten bada, hau da, pieza hasieratik amaiera arte arku elektrikoa itzali gabe fabrikatzen bada.

\subsection{Fabrikazio zuzena}

Fabrikazio zuzenaren barruan sartzen dira funtzio konkretu bat betetzeko sortutako piezak; hau da, bukaerako piezak fabrikatzen direnean, fabrikazio zuzena dela esaten da. Esaterako, 4. irudian ikusten den pieza euskarri multzo bateko pieza bat da; dorre bat, eta bere diseinu originala 4. (a) irudian ikus daiteke. WAAM teknologiaren bidez geometria konplexuagoak fabrika daitezkeenez, piezaren diseinua topologikoki optimizatu egin da (4. (b) irudia); hau da, pisu-murrizpen handiak lortu dira - kasu honetan, \% 31 ingurukoak - eta materialaren erabilera-efizientzia handitu da. 4. (c) irudian, WAAM bidez 5356 aluminio-aleazioan fabrikatutako pieza ageri da. 3. taulan pieza hau fabrikatzeko parametroak ikus daitezke.

3. taula. 5356 aluminio-aleazioan ezarritako dorrearen fabrikazio-parametroak.

\begin{tabular}{c|c|c|c|c}
\hline Modua & $\begin{array}{c}\text { Hariaren elikatze } \\
\text { abiadura }(\mathrm{m} / \mathrm{min})\end{array}$ & $\begin{array}{c}\text { Aitzinamendu-abiadura } \\
(\mathrm{cm} / \mathrm{min})\end{array}$ & $\begin{array}{c}\text { Ezarpen-tasa } \\
(\mathrm{kg} / \mathrm{h})\end{array}$ & $\begin{array}{c}\text { Fabrikazio } \\
\text { denbora }(\mathrm{h})\end{array}$ \\
\hline Pulsed-AC & 8 & 168 & 1,44 & 5 \\
\hline
\end{tabular}

Pieza hori Pulsed-AC soldadura modua erabilita fabrikatu da, babesgasa, $\mathrm{Ar} \%$ 100, $30 \mathrm{~L} / \mathrm{min}$-ko emariarekin sartuz prozesuan. Pieza geruzaz geruza fabrikatu da, lehenik eta behin, soldadura kordoi baten bidez piezaren ingurua ezarriz eta ondoren barnealdea raster edo oszilazio-mugimendu 
batekin betez. Soldadura-kordoien gainezarpena $3 \mathrm{~mm}$-koa izan da oszilazio-estrategian, eta ezarritako geruzaren altuera $1,5 \mathrm{~mm}$-koa. Kasu horretan, ez da hozte-denbora bat ezarri beharrik izan geruzen artean, eta oinarrimaterial gisara piezaren material bereko $15 \mathrm{~mm}$-ko plaka laua erabili da.

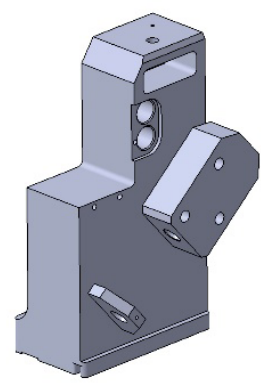

(a)

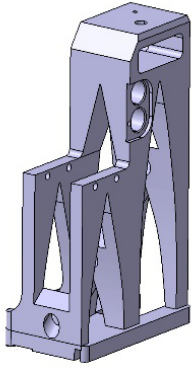

(b)

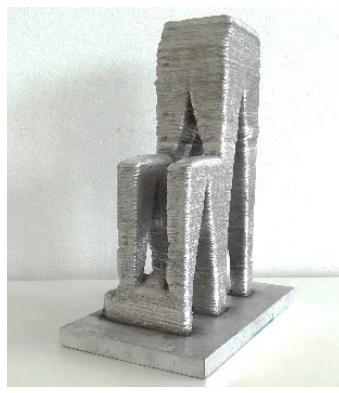

(c)

4. irudia. (a) Dorrearen diseinu originala; (b) WAAM teknologiarako prestatutako diseinu topologikoki optimizatua; (c) Pieza 5356 aluminioan fabrikatua, WAAM teknologia erabiliz.

\subsection{Fabrikazio ez-zuzena}

Aldiz, fabrikazio ez-zuzenean sartzen dira beste pieza batzuk fabrikatzeko sortutako piezak. Talde honetan ditugu, esaterako, moldeak, trokelak, matrizeak, etab. Adibide gisara, 5. irudiko moldea ER70S-6 aleazio baxuko altzairuan (0,06-0,12 arteko karbono edukia duena) fabrikatu da, GMAW soldaduran oinarritutako WAAM teknologia erabiliz. 4. taulan moldea fabrikatzeko erabilitako parametroak azaltzen dira.

4. taula. ER70S-6 altzairuan moldea fabrikatzeko-parametroak.

\begin{tabular}{c|c|c|c|c}
\hline Modua & $\begin{array}{c}\text { Hariaren elikatze } \\
\text { abiadura }(\mathrm{m} / \mathrm{min})\end{array}$ & $\begin{array}{c}\text { Aitzinamendu-abiadura } \\
(\mathrm{cm} / \mathrm{min})\end{array}$ & $\begin{array}{c}\text { Ezarpen-tasa } \\
(\mathrm{kg} / \mathrm{h})\end{array}$ & $\begin{array}{c}\text { Fabrikazio } \\
\text { denbora }(\mathrm{h})\end{array}$ \\
\hline Cold Arc & 5 & 65 & 2,66 & $27 \mathrm{~h} 39 \mathrm{~min}$ \\
\hline
\end{tabular}

Gainera, fabrikazio hau jarraia izan da, hau da, arkua piztu eta gelditu gabe modu jarraian fabrikatu da moldea. Bertan erabilitako soldadura modua Cold Arc izan da. Kasu honetan, babes-gasa, \% $18 \mathrm{CO}_{2}{ }^{-} \% 82 \mathrm{Ar}$, $17 \mathrm{~L} /$ min-ko emariarekin sartu da prozesuan eta oinarri-material gisara, $12 \mathrm{~mm}$-ko S235JR altzairuzko plaka laua erabili da. Geruza bakoitzaren altuera 1,3 mm-tan ezarri da. 


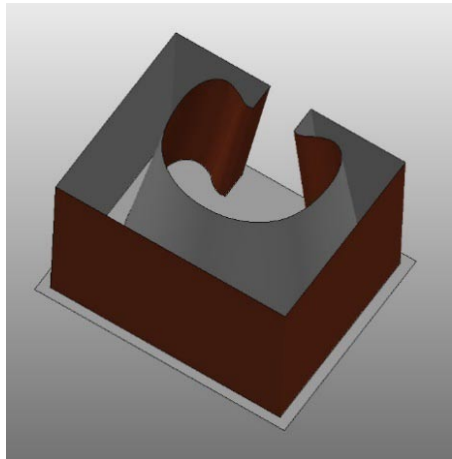

(a)

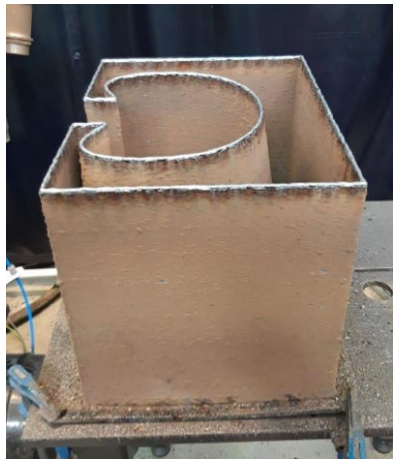

(b)

5. irudia. (a) Moldearen diseinua; (b) Moldea ER70 altzairuan fabrikatua, WAAM teknologia erabiliz.

\subsection{Konponketak}

WAAM prozesua erabileraren ondorioz kaltetutako piezak konpontzeko ere erabil daiteke. Pieza higatuta dagoen aldean, behar den material kantitatea gehitzen da WAAM prozesuaren bidez, eta, ondorengo mekanizazioari esker, pieza berria bezala geratzen da. Adibide gisara, konpondutako molde bat agertzen da 6. irudian. Konponketa hau Pulsed-GMAW modua erabilita gauzatu da, H13 erraminta-altzairuan. Babes-gas gisara, $\% 18 \mathrm{CO}_{2}-\% 82$ Ar nahastea erabili da, 17 L/min-ko emariarekin. Kasu honetan, higatutako moldearen (oinarri-materiala) eta ezarritako materialaren arteko interfasearen propietateak arretaz zaindu behar izan dira.
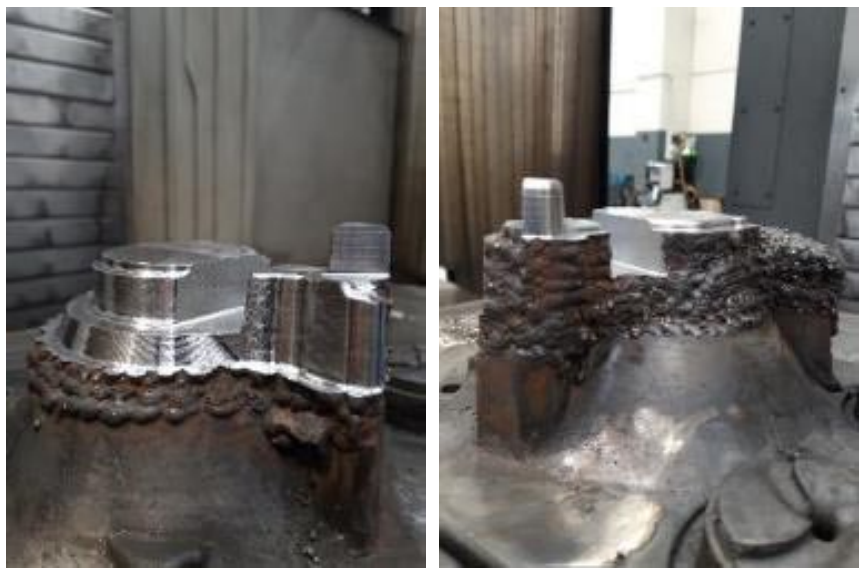

6. irudia. Konpondutako moldea. 


\section{ONDORIOAK}

Ikusi denez, etorkizun handia izan dezakeen fabrikazio-gehigarriko tekniketako bat da WAAM teknologia. Izan ere, teknika horrek ezarpentasa altuak lortzen ditu ingeniaritzako material metaliko anitzetan, eta, beraz, oso egokia izan daiteke tamaina ertain-handiko piezen fabrikaziorako. Gainera, fabrikazio-teknika tradizionalekin alderatuz, diseinu-mugak zabal daitezke, eta erabiltzen den material kantitatea murriztu, materialaren erabilera-efizientzia handituz.

Hala, artikulu honetan zehaztu diren aplikazioekin, hainbat sektore industrialen birmoldaketa eragingo duela uste da. Horretarako, WAAM teknologiaren monitorizazio eta kontrolaren inguruko ikerketa bultzatu beharko da oraindik, eta sakonki aztertu beharko da teknologia maila industrialean nola kudeatu. Horrez gain, prozesuaren aldaera ezberdinak ongi landu beharko dira, eta material berrien aukera ere aztertu beharko da.

\section{ESKER ONAK}

Eskerrak Eusko Jaurlaritzari, emandako finantzaketagatik.

\section{BIBLIOGRAFIA}

[1] Dilberoglu, U. M., Gharehpapagh, B., Yaman, U., Dolen, M. 2017. «The Role of Additive Manufacturing in the Era of Industry 4.0». Procedia Manufacturing, 11, 545-554.

[2] Wu, B., Pan, Z., Ding, D., Cuiuri, D., Li, H., Xu, J., Norrish, J. 2018. «A review of the wire arc additive manufacturing of metals: properties, defects and quality improvement». Journal of Manufacturing Processes, 35, 127-139.

[3] Williams, S. W., Martina, F., Addison, A. C., Ding, J., Pardal, G., ColeGROVE, P. 2016. «Wire + Arc Additive Manufacturing». Materials Science and Technology, 32, 641-647.

[4] Cook, P. S., Murphy, A. B. 2020. «Simulation of melt pool behaviour during additive manufacturing: Underlying physics and progress». Additive Manufacturing, 31, 100909.

[5] Ding, D., PAN, Z., Cuiuri, D., Li, H. 2015. «Robotics and Computer-Integrated Manufacturing A multi-bead overlapping model for robotic wire and arc additive manufacturing (WAAM )». Robotics and Computer Integrated Manufacturing, 31, 101-110.

[6] Sames, W. J., List, F. A., Pannala, S., Dehoff, R. R., Babu, S. S. 2016. «The metallurgy and processing science of metal additive manufacturing». International Materials Reviews, 61, 315-360. 
[7] Zhang, Y., Wu, L., Guo, X., Kane, S., Deng, Y., Jung, Y. G., Lee, J. H., ZHANG, J. 2018. «Additive Manufacturing of Metallic Materials: A Review». Journal of Materials Engineering and Performance, 27, 1-13.

[8] FrazIER, W. E. 2014. «Metal additive manufacturing: A review». Journal of Materials Engineering and Performance, 23, 1917-1928.

[9] Wong, K. V., Hernandez, A. 2012. «A Review of Additive Manufacturing». ISRN Mechanical Engineering, 2012, 1-10.

[10] Agote, I. 2018. «Fabricación Aditiva de Metales : Aplicaciones industriales de WAAM, LMD y 3DP».

[11] Aldalur, E., Veiga, F., Suárez, A., Bilbao, J., Lamikiz, A. 2020. «High deposition wire arc additive manufacturing of mild steel: Strategies and heat input effect on microstructure and mechanical properties». Journal of Manufacturing Processes, 58, 615-626.

[12] DEREKAR, K. S. 2018. «A review of wire arc additive manufacturing and advances in wire arc additive manufacturing of aluminium». Materials Science and Technology, DOI: 10.1080/02670836.2018.1455012.

[13] Rodrigues, T. A., Duarte, V., Miranda, R. M., Santos, T. G., Oliveira, J. P. 2019. «Current status and perspectives on wire and arc additive manufacturing (WAAM)». Materials, 12, 1121.

[14] Cunningham, C. R., Flynn, J. M., Shokrani, A., Dhokia, V., Newman, S. T. 2018. «Invited review article: Strategies and processes for high quality wire arc additive manufacturing». Additive Manufacturing, 22, 672-686.

[15] Busachi, A., Erkoyuncu, J., Colegrove, P., Martina, F., Watts, C., DRAKE, R. 2017. «A review of Additive Manufacturing technology and Cost Estimation techniques for the defence sector». CIRP Journal of Manufacturing Science and Technology, 19, 117-128.

[16] Ding, D., PAN, Z., CuIURI, D., LI, H. 2015. «A multi-bead overlapping model for robotic wire and arc additive manufacturing (WAAM)». Robotics and Computer-Integrated Manufacturing, 31, 101-110.

[17] UhrLANDT, D. 2016. «Diagnostics of metal inert gas and metal active gas welding processes». Journal of Physics D: Applied Physics, 49, DOI: 10.1088/0022-3727/49/31/313001.

[18] Herzog, D., Seyda, V., Wycisk, E., Emmelmann, C. 2016. «Additive manufacturing of metals». Acta Materialia, 117, 371-392.

[19] Aldalur, E., Veiga, F., Suárez, A., Bilbao, J., Lamikiz, A. 2020. «Analysis of the wall geometry with different strategies for high deposition wire arc additive manufacturing of mild steel». Metals, 10, 1-19. 